\title{
MiR-124 is differentially expressed in derivatives of the sympathoadrenal cell lineage and promotes neurite elongation in chromaffin cells
}

\author{
Stella Shtukmaster ${ }^{1}$ - Priyanka Narasimhan ${ }^{1}$ - Tehani El Faitwri ${ }^{1}$. Jutta Stubbusch ${ }^{2,3}$. \\ Uwe Ernsberger $^{2,3}$ • Hermann Rohrer ${ }^{2,3}$ • Klaus Unsicker ${ }^{1}$ • Katrin Huber ${ }^{1,4}$
}

\begin{abstract}
The neural-crest-derived sympathoadrenal cell lineage gives rise to sympathetic neurons and to endocrine chromaffin cells of the adrenal medulla. Both cell types express a largely overlapping set of genes, including those coding for the molecular machinery related to the synthesis and exocytotic release of catecholamines. During their early development, sympathetic neurons and chromaffin cells rely on a shared transcription factor network that controls the establishment of these common features. Despite many similarities, mature sympathetic neurons and chromaffin cells significantly differ regarding their morphology and function. Most prominently, sympathetic neurons possess axons that are absent in mammalian adrenal chromaffin cells. The molecular mechanism underlying the divergent development of sympathoadrenal cells into neuronal and endocrine cells remains elusive. Mutational inactivation of the ribonuclease dicer hints at the importance of microRNAs in this
\end{abstract}

Stella Shtukmaster, Priyanka Narasimhan and Tehani El Faitwri contributed equally to this work.

This work was supported by a grant from the DFG to H.R. and U.E. (RO469/12-1) and K.U. (UN 34/24-1).

Katrin Huber

katrin.huber@unfr.ch

Institute of Anatomy and Cell Biology, Department of Molecular Embryology, Albert-Ludwigs-University, Albertstr. 17, 79104 Freiburg, Germany

2 Research Group Developmental Neurobiology, Max-Planck-Institute for Brain Research, Max-von-Laue-Strasse 4, 60438 Frankfurt/ Main, Germany

3 Institute of Clinical Neuroanatomy, Goethe University Frankfurt/M, Theodor-Stern-Kai 7, 60590 Frankfurt/M, Germany

4 Department of Medicine, University of Fribourg, Route-Albert-Gockel 1, 1700 Fribourg, Switzerland diversification. We show here that miR-124 is detectable in developing sympathetic neurons but absent in chromaffin cell precursors. We further demonstrate that miR-124 promotes neurite elongation when transfected into cultured chromaffin cells indicating its capability to support the establishment of a neuronal morphology in non-neuronal sympathoadrenal cells. Our results also show that treatment of PC12 cells with the neurotrophin nerve growth factor leads to an upregulation of miR-124 expression and that inhibition of miR-124 reduces nerve-growthfactor-induced neurite outgrowth in PC12 cells. Thus, our data indicate that miR-124 contributes to the establishment of specific neuronal features in developing sympathoadrenal cells.

Keywords miR-124 $\cdot$ Chromaffin cell $\cdot$ Sympathoadrenal cell lineage $\cdot$ Sympathetic neuron $\cdot$ Mouse

\section{Introduction}

MicroRNAs (miRNAs) are endogenous small non-coding RNAs that play a pivotal role in post-transcriptional gene regulation, in particular gene silencing (McManus and Sharp 2002). They exert their function by binding to the 3 '-untranslated region of their target mRNAs and thus either induce mRNA degradation (Guo et al. 2010; Hendrickson et al. 2009) or inhibit translation (Mathonnet et al. 2007; Thermann and Hentze 2007). Results from mice carrying conditional null mutations for dicer, an enzyme required for the cleavage of pre-miRs into mature miRs (Bernstein et al. 2001), indicate the essential role of miRNAs in many cellular processes (Cuellar et al. 2008; Davis et al. 2011; Harris et al. 2006; Harfe et al. 2005; Nagalakshmi et al. 2011). MicroRNAs are believed to contribute to the specification and differentiation of various cell types including neurons (Åkerblom et al. 2012; Yu et al. 2008; Stappert et al. 2013). 
MiR-124 is a highly conserved microRNA preferentially expressed in the nervous system. Several studies have suggested that miR-124 plays a role in neurogenesis (Åkerblom et al. 2012; Visvanathan et al. 2007) and neurite outgrowth (Yu et al. 2008).

Sympathetic neurons and chromaffin cells are both derived from common progenitors from the neural crest (Shtukmaster et al. 2013) and share the capability to store, synthesize and release catecholamines. Their common molecular markers include, inter alia, the enzymes for noradrenaline synthesis, namely tyrosine-hydroxylase (TH) and dopamine- $\beta$-hydroxylase (DBH). However, as endocrine and neuronal cells, they are distinct in their morphology and function. Whereas sympathetic neurons reach their peripheral targets via axons and release noradrenaline as a neurotransmitter on varicosities, chromaffin cells store adrenaline and noradrenaline in large vesicles and release them upon stimulation into the blood stream. Despite these differences, the precursors of both cell types rely on a similar gene regulatory network that governs their early development from neural crest cells into catecholaminergic sympathoadrenal (SA) cells (for reviews, see Huber et al. 2009; Huber 2015). This includes a shared set of pro-neural transcription factors comprising, among others, Phox2/B, Mash1 and Hand2 (for reviews, see Huber 2006; Rohrer 2011). Given the similarity between sympathetic neuron and chromaffin cell precursors regarding their combinatorial transcription factor code, their divergent development into neuronal and endocrine cells remains enigmatic.

We have shown recently that the microRNA-producing enzyme dicer plays an important role in the development of both sympathetic neurons and chromaffin cells by affecting their survival and contributing to the establishment of their respective specific gene expression pattern (Stubbusch et al. 2013). In particular, dicer inactivation compromises transcript accumulation for synaptic proteins in sympathetic neurons and repression of neurofilaments in chromaffin cells, features characteristic for neuronal and endocrine cells, respectively. We show here that miRNA-124 is expressed by neuronal but not by endocrine derivatives of the SA cell lineage and that forced expression of miR-124 promotes neurite outgrowth from cultured chromaffin cells indicating that the acquisition of specific neuronal traits in SA cells is, at least in part, regulated by miR-124.

\section{Materials and methods}

\section{Animals}

For histology and primary chromaffin cell cultures, pregnant mice were killed by cervical dislocation and embryos were removed. Embryonic age was determined by designating the day of the vaginal plug as E0.5.

\section{Histology}

Embryos were rinsed in phosphate buffer (PB, $\mathrm{pH}$ 7.4) and fixed in $4 \%$ paraformaldehyde (PFA) in PB overnight at $4{ }^{\circ} \mathrm{C}$. Fixed embryos were rinsed three times in $\mathrm{PB}$ and transferred to $30 \%$ sucrose in $\mathrm{PB}$ overnight at $4{ }^{\circ} \mathrm{C}$. Tissues were frozen in Tissue-Tek O.C.T. Compound (Sakura Finetek) and stored at $-80{ }^{\circ} \mathrm{C}$ until further processed. In situ hybridization and preparation of digoxigenin-labelled probes for mouse DBH (Tiveron et al. 1996) and mouse steroidogenic factor 1 (SF-1; Gut et al. 2005) were performed on 10- $\mu \mathrm{m}$-thick cryosections as described previously (Ernsberger et al. 1997). MiR-124 in situ hybridization was carried out on $10-\mu \mathrm{m}$-thick cryosections as described previously (Stubbusch et al. 2013) by using a 5' digoxigenin-labelled RNA modified probe for miR124 (88066-01 Exiqon, Vedbaek, Denmark) and scrambled control (99004-01, Exiqon).

\section{Primary chromaffin cell culture}

Adrenals of E16.5 mouse embryos were dissected and freed from the surrounding capsule. Tissues were collected in $\mathrm{Mg}^{2+}$ - and $\mathrm{Ca}^{2+}$-free Hanks' balanced solution (CMF) and sequentially digested with $0.1 \%$ collagenase (Life Technologies, Darmstadt, Germany) for $30 \mathrm{~min}$ at $37{ }^{\circ} \mathrm{C}$ and $0.125 \%$ trypsin (Life Technologies) for $10 \mathrm{~min}$ at $37{ }^{\circ} \mathrm{C}$. The digestion was stopped with fetal bovine serum (FBS) and tissue was triturated into single-cell suspensions with narrow-bored fire-polished Pasteur pipettes by using $2 \mathrm{ml} \mathrm{CMF,} 1 \mathrm{ml}$ FBS and $10 \mu \mathrm{l}$ DNase. After being washed, the cells were resuspended in $100 \mu \mathrm{l}$ Nucleofector Solution (Lonza, Basel, Switzerland) at room temperature and electroporated with pCMV-MIR control vector (Origene, Rockville, USA) or pCMV-MIR-124 (MI0000717, Origene) by using an Amaxa Nucleofector according to the manufacturer's instructions (program A33). Subsequently, the cells were re-suspended in Dulbecco's modified eagle medium (DMEM, Life Technologies) containing N1 supplements (N-6530, Sigma, Munich, Germany) and seeded at a density of $5 \times 10^{4}$ cells/well on poly-L-ornithine/laminin-coated glass coverslips (diameter $8 \mathrm{~mm}$ ) in 24-well culture plates. Cultures were maintained in a humidified $5 \% \mathrm{CO}_{2} / 95 \%$ air atmosphere at $37{ }^{\circ} \mathrm{C}$ for 4 days in control medium or medium containing $15 \mu \mathrm{M}$ Rho-kinase inhibitor Y27632 (Sigma, $15 \mu \mathrm{M})$. Half of the medium was replaced with fresh medium every $48 \mathrm{~h}$. 


\section{Immunocytochemistry}

Cultured adrenal cells were fixed with $4 \%$ PFA for $10 \mathrm{~min}$ at room temperature, washed 3 times for $5 \mathrm{~min}$ in phosphate-buffered-saline (PBS) at room temperature and pretreated with blocking agent (BA) consisting of PBS containing $0.1 \%$ Triton X-100 and $1 \%$ bovine serum albumin. Subsequently, cells were incubated with sheep anti-TH antibody (1:1000 in BA; AB1542, Millipore, Schwalbach, Germany) and rabbit anti-green fluorescent protein (anti-GFP; 1:200 in BA; AB290, Abcam, Cambridge, UK) overnight at $4{ }^{\circ} \mathrm{C}$. Coverslips were washed three times with PBS for 5 min each and incubated with Alexa594-conjugated donkey anti-sheep antibody (1:400; Dianova, Hamburg, Germany) and Alexa488conjugated donkey anti-rabbit antibody $(1: 400$; Dianova). Cells were rinsed with PBS three times for 5 min and mounted with Fluoro-Mount containing 4,6diamidino-2-phenylindole (Dianova).

\section{Analysis of neurite length}

The neurite length of chromaffin cells was analyzed by using an Axioplan 2 (Zeiss, Göttingen, Germany) equipped with an AxioCamHR (Zeiss). The average neurite length was determined with NeuronJ by assessing at least 70 randomly selected cells per group and experiment (at least three independent experiments per group). The two-tailed $t$-test was used for statistical evaluation. A $P$-value less than $0.05 \%$ (*) was considered as statistically significant.

\section{PC12 cultures and quantitative polymerase chain reaction}

PC12-cells were seeded at a density of $2.5 \times 10^{4}$ cells/ well on poly-L-ornithine/laminin-coated 6-well culture plates and cultured in control medium (DMEM supplemented with $10 \% \mathrm{FBS}, 5 \%$ horse serum and $1 \%$ penicillin/streptomycin) or medium containing $50 \mathrm{ng} / \mathrm{ml}$ nerve growth factor (hNGF; R\&D Systems, Wiesbaden, Germany). After $6 \mathrm{~h}, 24 \mathrm{~h}$ and 6 days in culture, the cells were harvested and RNA was extracted by using a miRNeasy Minikit (Qiagen, Hilden, Germany) according to the manufacturer's instructions. cDNA was synthesized by reverse transcription (RT) with a miScript RT II kit (Quiagen). Subsequently, real-time polymerase chain reaction (PCR) was performed with a miScript SYBR green PCR kit (Qiagen) and primers for miR-124 (MS00005593, Qiagen) and RNU6-2 (MS00033740, Qiagen) according to the manufacturer's instructions. Relative miR-124 expression levels were determined by the ddCT method by using RNU6-2 expression levels for
Fig. 1 In situ hybridization on sections of an E16 mouse adrenal gland with a probe for miR-124 (c) and a scrambled (src) control probe (d). Steroidogenic factor 1 $(s f-1)$ and dopamine- $\beta$ hydroxylase $(d b h)$ in situ hybridization was carried out on near adjacent sections to mark the adrenal cortex and adrenal chromaffin cells, respectively (a, b). Note that miR-124 is undetectable in the adrenal gland but clearly present in the adjacent suprarenal ganglion ( $s r g$ ). The border of the adrenal gland is demarcated by a dashed line. Bar $100 \mu \mathrm{m}$
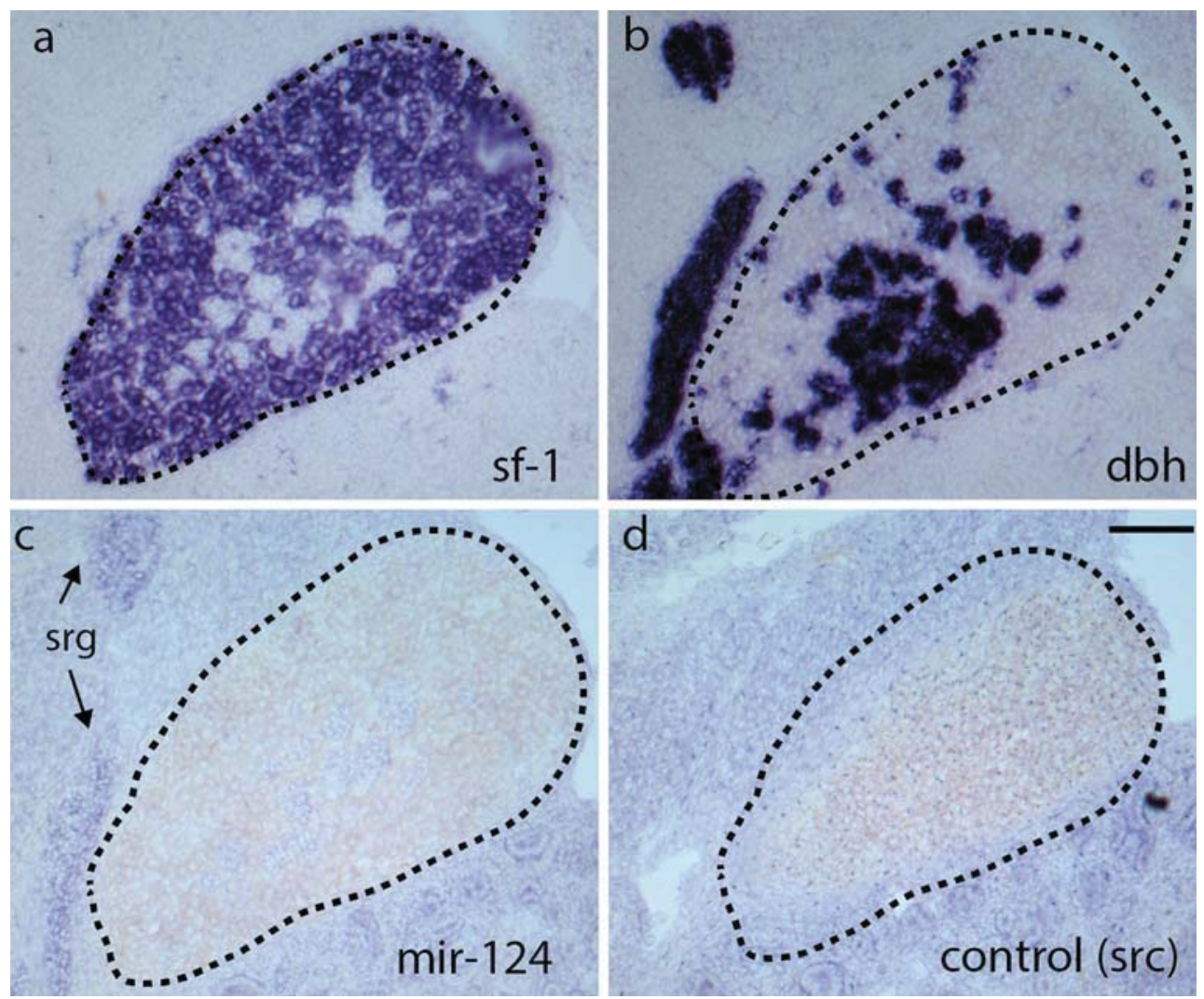
normalization. The two-tailed $t$-test was employed for statistical evaluation. A $P$-value less than $0.05 \%\left(^{*}\right)$ was considered as statistically significant.

For the miR-124 inhibitor experiments, PC12 cells were seeded on poly-L-ornithine/laminin-coated glass coverslips (diameter $8 \mathrm{~mm}$ ) in 24-well culture dishes and incubated in culture medium containing $50 \mathrm{ng} / \mathrm{ml} \mathrm{hNGF}$ in the presence of miR-124 miRCURY LNA Power microRNA inhibitor (Exiqon) or miRCURY LNA Power microRNA control inhibitor (Exiqon). After 3 days in culture, the cells were fixed and TH immunostaining was performed as described above. Subsequently, the percentage of cells carrying at least one process whose length was at least 1.5 times the cellular diameter was evaluated.

\section{Results}

\section{MiR-124 is differentially expressed in neuronal and endocrine SA derivatives}

Our micro-RNA expression profiling studies of mouse adrenal glands and sympathetic ganglia by quantitative PCR (qPCR) have indicated that several microRNAs are expressed at differential levels in these tissues (unpublished results). MiR-124 was present in sympathetic ganglia but was completely undetectable in adrenal glands. In confirmation of the profiling results, we have previously shown that miR-124 can be detected by in situ hybridization in developing mouse sympathetic ganglia at E16.5 (Stubbusch et al. 2013). Here, we
Fig. 2 MiR-124 and treatment with the Rho-kinase inhibitor Y27632 promote neurite elongation in chromaffin cells (af) after 4 days in culture. Photomicrographs of chromaffin cells electroporated with PCMVMIR-miR-124 (a-c) or PCMVMIR control vector $(\mathbf{d}-\mathbf{f})$. Successfully electroporated chromaffin cells were labelled with antibodies against green fluorescent protein (GFP; green in a, d) and tyrosine-hydroxylase (TH; red in b, e). Overlay (c, f). Bar $50 \mu \mathrm{m}$. Quantitative analysis of neurite length $(\mathbf{g}, \mathbf{h})$. Note that treatment of miR-124-

electroporated chromaffin cells with inhibitor did not result in a further increase in neurite length (h). Both mir-124 and Y27632 in addition gave a slight nonsignificant increase in the number of cellular processes (i) and branching points (j). At least 30 randomly selected cells per group and experiment $(n=3)$ were evaluated. Data are presented as means \pm SEM. ${ }^{* *} P<0.01$
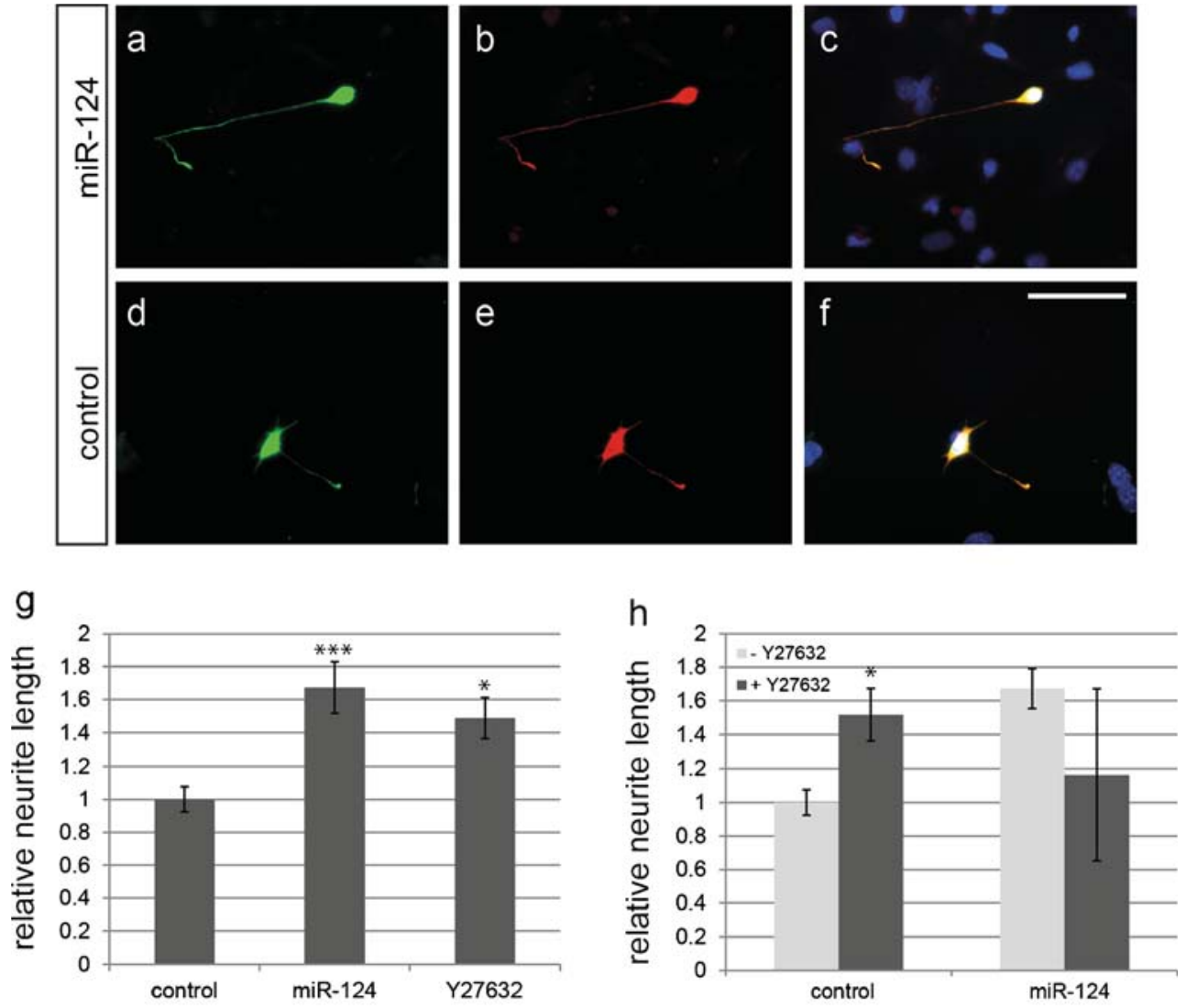

i

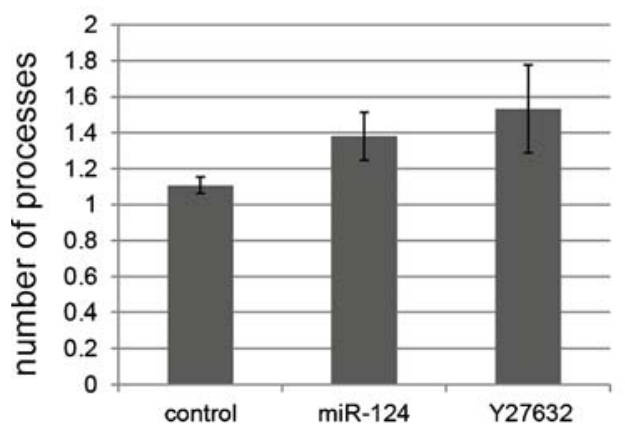

j

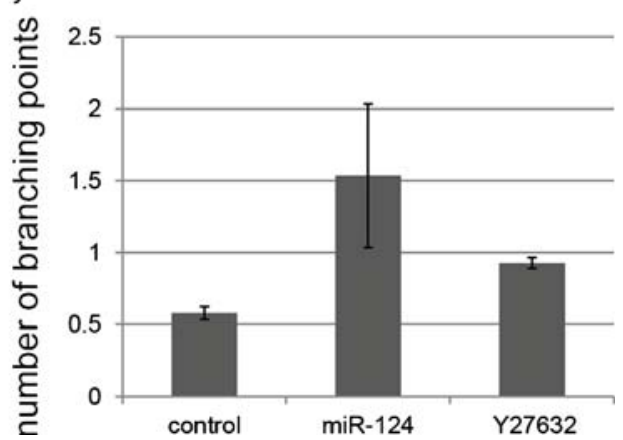




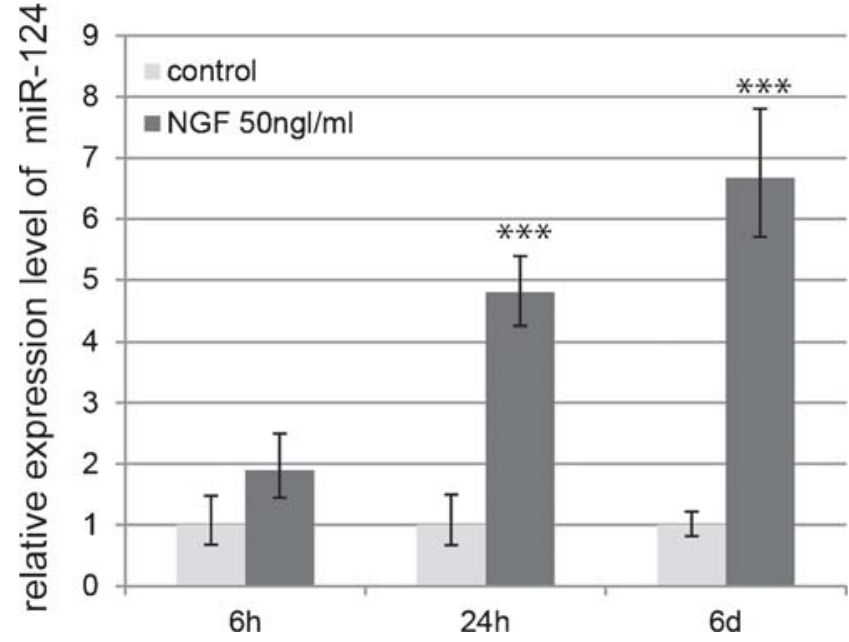

Fig. 3 Quantitative polymerase chain reaction (qPCR) analysis reveals enhanced expression of miR-124 in PC12 cells treated with nerve growth factor (NGF) for $6 \mathrm{~h}, 24 \mathrm{~h}$ and 6 days as compared with untreated cells. Data are presented as means $\pm \operatorname{SEM}(n=5) .{ }^{*} P<0.05$

analyzed miR-124 expression in the E16.5 adrenal gland by in situ hybridization. As shown in Fig. 1, neither chromaffin cells of the adrenal medulla nor the adrenal cortex exhibit a signal above background, whereas the adjacent sympathetic suprarenal ganglion is clearly positive. Faint in situ hybridization signals for miR-124 could also be observed in early sympathetic ganglia (E12.5-E14.5; not shown), suggesting that miR124 expression is initiated at early stages of sympathetic neuron development. These findings corroborate the profiling

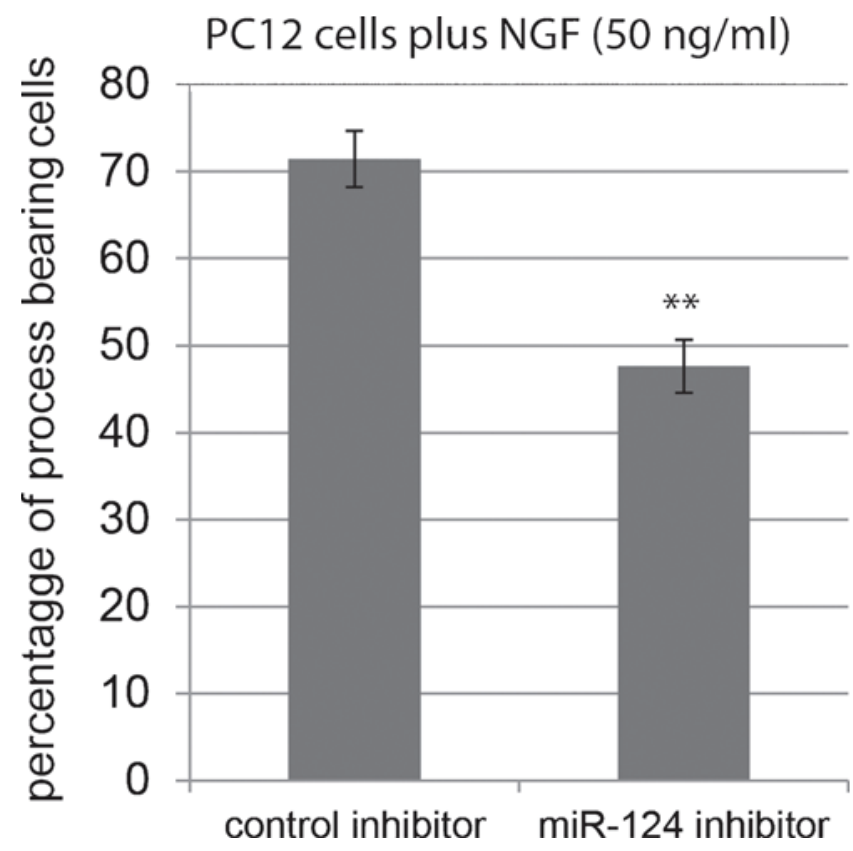

Fig. 4 Percentage of $\mathrm{PC} 12$ cells exhibiting processes after 3 days in culture in the presence of NGF $(50 \mathrm{ng} / \mathrm{ml})$ and a miR-124 inhibitor or a control inhibitor. At least 100 cells per group and experiment $(n=3)$ were evaluated. Data are presented as means $\pm \operatorname{SEM}(n=3) . * * P<0.05$ data and indicate miR-124 as a putative candidate that specifically regulates neuronal differentiation in developing SA cells.

\section{MiR-124 enhances neurite elongation in cultured adrenal chromaffin cells}

To address the question as to whether miR-124 supports the establishment of neuronal features in non-neuronal SA cells, we employed E16.5 mouse adrenal gland dissociation cultures. Before plating, the cells were electroporated with either miR-124-PCMV/GFP-constructs or controlPCMV/GFP-constructs. Chromaffin cells that had been successfully electroporated were identified by TH-/GFPdouble-immunostaining. After 1 day in culture, the TH/ GFP-positive cells had a rounded morphology and did not extend any processes in either the control cultures or the cultures electroporated with the miR-124 construct (not shown). After 4 days in vitro, many TH/GFP-positive cells had grown processes, even in control cultures. However, the average length of these processes was strongly enhanced in cultures electroporated with miR124-PCMV/GFP-constructs, indicating that miR-124 supports neurite elongation from cultured chromaffin cells (Fig. 2). In miR-124 electroporated chromaffin cells, a small non-significant increase in the average number of cytoplasmatic processes and neuritic branching points per cell could additionally be observed. The Rho-kinase Rock1 is one of the direct targets of miR-124; this has been linked to its effect on neurite outgrowth. As shown in Fig. 2g, the addition of the Rho-kinase inhibitor Y27632 to chromaffin cells that were electroporated with control plasmid had an effect on neurite formation comparable with that of miR-124. The treatment of miR-124electroporated chromaffin cells with Y27632 did not promote a further increase of neurite elongation (Fig. 2h).

\section{MiR-124 expression is upregulated in PC12 cells upon NGF treatment}

Developing chromaffin cells have the capability to undergo neuron-like differentiation in response to extrinsic signals such as NGF (Unsicker et al. 1978; Ogawa et al. 1986). To test whether this is accompanied by the upregulation of miR-124, we employed PC12 cells, a chromaffin-cell line derived from a pheochromocytoma of the rat adrenal medulla (Greene and Tischler 1976). We could not use primary chromaffin cell cultures for this purpose because of the limited amount of RNA that could be extracted from these cells. We treated PC12 cells with NGF $(50 \mathrm{ng} / \mathrm{ml}$ ), which has been shown efficiently to induce neuron-like features in PC12 cells (Schimmelpfeng et al. 2004), for 6 h, 24 h and 6 days. 
Fig. 5 MiR-124 pathways that possibly contribute to the establishment of neuron-specific properties in the neuronal progeny of the sympathoadrenal (SA) lineage. The precursors of sympathetic neurons and chromaffin cells share a virtually identical set of transcription factors (TFs), including Phox2B, which is required for the establishment of

catecholaminergic and neuronal features (for a review, see Huber 2015). MiR-124 is only present in the neuronal progeny of the SA lineage and has been shown to target SCP-1 (Visvanathan et al. 2007), an antagonist of neuronal gene expression and to repress the Rho-kinase Rock1 (Gu et al. 2014), leading to enhanced neurite outgrowth $(S C P-1$ small C-terminal domain phosphatase 1)

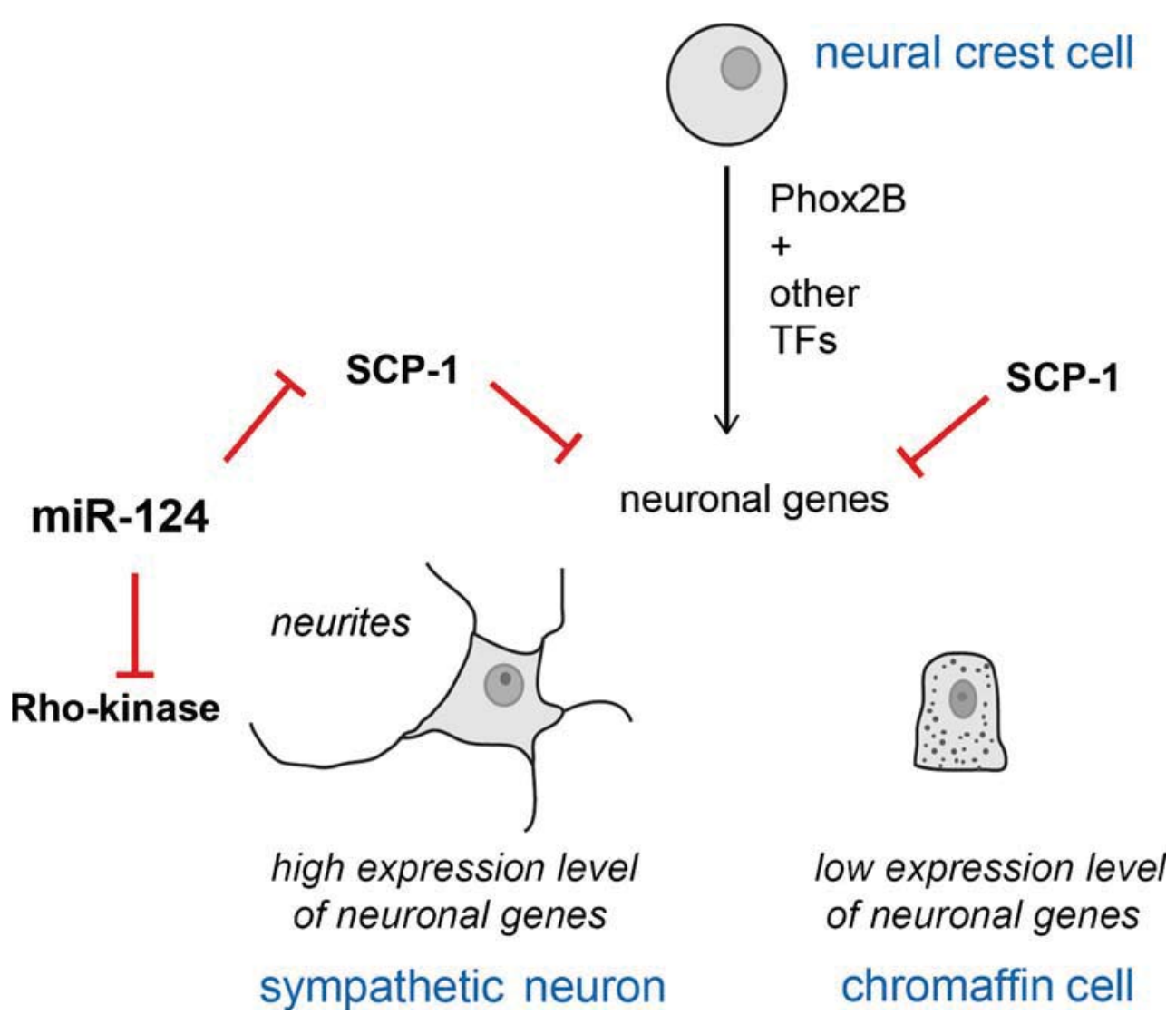

RNA was extracted from the PC12 cells and qPCR was performed. As shown in Fig. 3, NGF treatment significantly increased miR-124 expression levels as compared with that of untreated cells after $24 \mathrm{~h}$. The miR-124 levels remained elevated at least until 6 days after addition of NGF. A small non-significant increase of miR-124 expression levels was observed even after $6 \mathrm{~h}$ of NGF treatment, before obvious morphological changes could be observed in PC12 cells.

\section{Inhibition of miR-124 reduces NGF-induced neurite outgrowth from PC-12 cells}

We next addressed the question as to whether the induction of neurite outgrowth, one of the major effects of NGF on PC12 cells, is mediated by miR-124. For this purpose, we cultured PC12 cells in the presence of NGF and an miR-124 miRCURY LNA Power inhibitor or a control inhibitor. Whereas virtually no neurite outgrowth was observed in PC12 cells cultured without NGF, the majority of NGFtreated PC12 cells exhibited processes after 3 days. The addition of a miR-124 inhibitor to the NGF-treated PC12 cells resulted in a significant decrease of the percentage of PC12 cells carrying processes, as compared with the addition of a control inhibitor but did not completely abolish neurite outgrowth from PC12 cells (Fig. 4).

\section{Discussion}

SA cells segregate into neuronal and endocrine cells and thus provide an intriguing model for studying fundamental developmental mechanisms underlying the generation of these cell types. Whereas sympathetic neurons and chromaffin cells share the molecular pathways of catecholamine synthesis and regulated release, their morphology and function are overtly different. Despite these differences, the intrinsic molecular players that govern the early development of both cell types are apparently similar (Huber 2006, 2015). Early intrinsic cues that promote neuronal versus endocrine differentiation or vice versa have not been identified as yet.

We show here that miR-124 is present in developing sympathetic neurons but absent in chromaffin cell progenitors of the adrenal medulla in vivo and that it is capable of promoting neurite elongation from cultured chromaffin cells. In addition, we observed that neuron-like differentiation of PC12 cells evoked by NGF is accompanied by the upregulation of miR124 and that inhibition of miR-124 reduces neurite outgrowth from PC12. Taken together, these findings support the notion that miR-124 is a key intrinsic cue that establishes neuronal morphology in developing SA cells and thus contributes to the diversification of SA cells.

microRNAs are believed to be involved in crucial steps of cell specification and differentiation in various tissues. Their 
ability to target multiple mRNAs allows them to orchestrate networks of pathways; this is particularly important for the execution of developmental programs within a short time frame. Several miRNAs are known to be associated with the nervous system, of which miR-124 is by far the most abundantly expressed (Kosik 2009; Lagos-Quintana et al. 2002). Although several studies have suggested important roles of miR-124 in various aspects of neural development, including neurogenesis, neuronal differentiation and neurite outgrowth (Åkerblom et al. 2012, Cheng et al. 2009, Yu et al. 2008), its physiological significance has remained controversial to date, since others have doubted its essential function in neural development (Cao et al. 2007). However, several direct miR-124 targets have been identified that possibly account for its putative role in neural development, including the small GTPase Rho kinase Rock1. The repression of Rock1 by miR-124 has been linked to its role in neurite elongation ( $\mathrm{Gu}$ et al. 2014). Our data show that the addition of a Rho-kinase inhibitor to chromaffin cell cultures has a similar effect on neurite formation in chromaffin cells as does electroporation with miR-124. The effects of miR-124 and Rho-kinase inhibitor appear not to be additive, supporting the notion that miR-124 acts though the repression of Rho-kinases in chromaffin cells.

Our data also suggest that NGF-induced neurite outgrowth from PC12 cells is, at least in part, mediated by miR-124, since miR-124 is upregulated by NGF and its inhibition reduces NGF-provoked neurite outgrowth. Apart from its effect on neurite outgrowth, NGF has been shown to increase the expression of neuron-specific genes such as neurofilament or neuron-specific enolase in PC12 cells (Lee et al. 1982; Vinores et al. 1981). As miR-124 directly targets and represses the small C-terminal domain phosphatase 1 (SCP-1; Cheng et al. 2009; Visvanathan et al. 2007), an antagonist of the transcription of neuronal genes (Visvanathan et al. 2007), the NGF-induced acquisition of neuronal markers in PC12 might also, at least partially, be mediated by miR-124. Another direct target of miR-124 is polypyrimidine tract binding protein 1 (PTBP1), a repressor of neuron-specific alternative splicing. Its downregulation by miR-124 leads to the inclusion of neuron-specific exons into mature mRNA (Makeyev et al. 2007) and thus contributes to the establishment of a neuronspecific gene expression pattern.

Previous studies have suggested that microRNAs play important roles in the development of SA cells. The loss of the microRNA-processing enzyme dicer has been shown to severely reduce the survival of sympathetic neuron precursors (Huang et al. 2010; Zehir et al. 2010) and also partially to affect the establishment of their typical neuronal gene expression pattern (Stubbusch et al. 2013). Notably, sympathetic neurons of dicer-deficient mouse embryos exhibit reduced expression levels of synaptic marker genes and thus become more reminiscent of wildtype chromaffin cells in this respect. In view of the distinct expression of miR-124 in neuronal SA cells that we report here and of the putative role of miR-124 as a regulator of neuron-specific gene expression (Makeyev et al. 2007; Visvanathan et al. 2007), the loss of miR-124 might contribute to the altered gene expression pattern observed in the sympathetic neurons of dicer-deficient mice. Thus, in SA cells, miR-124 might function as an inducer of high expression levels of synaptic genes, in addition to its function in promoting neurite outgrowth. Figure 5 illustrates the way that miR-124 might contribute to the establishment of neuronspecific features in the neuronal progeny of the SA lineage.

In summary, our data are consistent with the notion that miR-124 is an intrinsic cue that supports the acquisition of neuronal characteristics in neural-crest-derived cells. These findings add to previous studies on the role of miR-124 in neuronal development and further underpin the notion that miR-124 is an important stimulus that promotes the acquisition of neuronal traits in the central and peripheral nervous systems. In the future, specific in vivo gain and loss of function studies will be necessary to assess further the precise role of miR-124 in the development of various types of neurons, including those of the SA lineage.

Acknowledgments The authors thank Ute Baur and Ellen Gimbel for excellent technical assistance.

\section{References}

Åkerblom M, Sachdeva R, Barde I, Verp S, Gentner B, Trono D, Jakobsson J (2012) MicroRNA-124 is a subventricular zone neuronal fate determinant. J Neurosci 32:8879-8889. doi:10.1523/ JNEUROSCI.0558-12.2012

Bernstein E, Caudy AA, Hammond SM, Hannon GJ (2001) Role for a bidentate ribonuclease in the initiation step of RNA interference. Nature 409:363-366. doi:10.1038/35053110

Cao X, Pfaff SL, Gage FH (2007) A functional study of miR-124 in the developing neural tube. Genes Dev 21:531-536. doi:10.1101/gad. 1519207

Cheng L-C, Pastrana E, Tavazoie M, Doetsch F (2009) miR-124 regulates adult neurogenesis in the subventricular zone stem cell niche. Nat Neurosci 12:399-408. doi:10.1038/nn.2294

Cuellar TL, Davis TH, Nelson PT, Loeb GB, Harfe BD, Ullian E, McManus MT (2008) Dicer loss in striatal neurons produces behavioral and neuroanatomical phenotypes in the absence of neurodegeneration. Proc Natl Acad Sci U S A 105:5614-5619. doi:10.1073/ pnas.0801689105

Davis N, Mor E, Ashery-Padan R (2011) Roles for Dicer1 in the patterning and differentiation of the optic cup neuroepithelium. Development 138:127-138. doi:10.1242/dev.053637

Ernsberger U, Patzke H, Rohrer H (1997) The developmental expression of choline acetyltransferase (ChAT) and the neuropeptide VIP in chick sympathetic neurons: evidence for different regulatory events in cholinergic differentiation. Mech Dev 68:115-126

Greene LA, Tischler AS (1976) Establishment of a noradrenergic clonal line of rat adrenal pheochromocytoma cells which respond to nerve growth factor.Proc Natl Acad Sci U S A 73:2424-2428

Guo H, Ingolia NT, Weissman JS, Bartel DP (2010) Mammalian microRNAs predominantly act to decrease target mRNA levels. Nature 466:835-840. doi:10.1038/nature09267 
Gut P, Huber K, Lohr J, Brühl B, Oberle S, Treier M, Ernsberger U, Kalcheim C, Unsicker K (2005) Lack of an adrenal cortex in Sf1 mutant mice is compatible with the generation and differentiation of chromaffin cells. Development 132:4611-4619. doi:10.1242/dev. 02052

Gu X, Meng S, Liu S, Jia C, Fang Y, Li S, Fu C, Song Q, Lin L, Wang X (2014) miR-124 represses ROCK1 expression to promote neurite elongation through activation of the PI3K/Akt signal pathway. J Mol Neurosci 52:156-165. doi:10.1007/s12031-013-0190-6

Harfe BD, McManus MT, Mansfield JH, Hornstein E, Tabin CJ (2005) The RNaseIII enzyme Dicer is required for morphogenesis but not patterning of the vertebrate limb. Proc Natl Acad Sci U S A 102: 10898-10903. doi:10.1073/pnas.0504834102

Harris KS, Zhang Z, McManus MT, Harfe BD, Sun X (2006) Dicer function is essential for lung epithelium morphogenesis. Proc Natl Acad Sci U S A 103:2208-2213. doi:10.1073/pnas.0510839103

Hendrickson DG, Hogan DJ, McCullough HL, Myers JW, Herschlag D, Ferrell JE, Brown PO (2009) Concordant regulation of translation and mRNA abundance for hundreds of targets of a human microRNA. PLoS Biol 7:e1000238. doi:10.1371/journal.pbio. 1000238

Huang T, Liu Y, Huang M, Zhao X, Cheng L (2010) Wnt1-cre-mediated conditional loss of Dicer results in malformation of the midbrain and cerebellum and failure of neural crest and dopaminergic differentiation in mice. J Mol Cell Biol 2:152-163. doi:10.1093/jmcb/mjq008

Huber K (2006) The sympathoadrenal cell lineage: specification, diversification, and new perspectives. Dev Biol 298:335-343. doi:10. 1016/j.ydbio.2006.07.010

Huber K (2015) Segregation of neuronal and neuroendocrine differentiation in the sympathoadrenal lineage. Cell Tissue Res 359:333-341. doi:10.1007/s00441-014-1947-0

Huber K, Kalcheim C, Unsicker K (2009) The development of the chromaffin cell lineage from the neural crest. Auton Neurosci Basic Clin 151:10-16. doi:10.1016/j.autneu.2009.07.020

Kosik KS (2009) MicroRNAs tell an evo-devo story. Nat Rev Neurosci 10:754-759. doi:10.1038/nrn2713

Lagos-Quintana M, Rauhut R, Yalcin A, Meyer J, Lendeckel W, Tuschl T (2002) Identification of tissue-specific microRNAs from mouse. Curr Biol 12:735-739

Lee V, Trojanowski JQ, Schlaepfer WW (1982) Induction of neurofilament triplet proteins in PC12 cells by nerve growth factor. Brain Res 238:169-180

Makeyev EV, Zhang J, Carrasco MA, Maniatis T (2007) The microRNA miR-124 promotes neuronal differentiation by triggering brainspecific alternative pre-mRNA splicing. Mol Cell 27:435-448. doi:10.1016/j.molcel.2007.07.015

Mathonnet G, Fabian MR, Svitkin YV, Parsyan A, Huck L, Murata T, Biffo S, Merrick WC, Darzynkiewicz E, Pillai RS, Filipowicz W, Duchaine TF, Sonenberg N (2007) MicroRNA inhibition of translation initiation in vitro by targeting the cap-binding complex eIF4F. Science 317:1764-1767. doi:10.1126/science.1146067

McManus MT, Sharp PA (2002) Gene silencing in mammals by small interfering RNAs. Nat Rev Genet 3:737-747. doi:10.1038/nrg908
Nagalakshmi VK, Ren Q, Pugh MM, Valerius MT, McMahon AP, Yu J (2011) Dicer regulates the development of nephrogenic and ureteric compartments in the mammalian kidney. Kidney Int 79:317-330. doi:10.1038/ki.2010.385

Ogawa M, Ishikawa T, Ohta H (1986) Transdifferentiation of endocrine chromaffin cells into neuronal cells. Curr Top Dev Biol 20:99-110

Rohrer H (2011) Transcriptional control of differentiation and neurogenesis in autonomic ganglia. Eur J Neurosci 34:1563-1573. doi:10.1111/j.1460-9568.2011.07860.x

Schimmelpfeng J, Weibezahn K-F, Dertinger H (2004) Quantification of NGF-dependent neuronal differentiation of PC-12 cells by means of neurofilament-L mRNA expression and neuronal outgrowth. J Neurosci Methods 139:299-306. doi:10.1016/j.jneumeth.2004.05. 010

Shtukmaster S, Schier MC, Huber K, Krispin S, Kalcheim C, Unsicker K (2013) Sympathetic neurons and chromaffin cells share a common progenitor in the neural crest in vivo. Neural Dev 8:12. doi:10.1186/ 1749-8104-8-12

Stappert L, Borghese L, Roese-Koerner B, Weinhold S, Koch P, Terstegge S, Uhrberg M, Wernet P, Brüstle O (2013) MicroRNAbased promotion of human neuronal differentiation and subtype specification. PLoS ONE 8:e59011. doi:10.1371/journal.pone. 0059011

Stubbusch J, Narasimhan P, Huber K, Unsicker K, Rohrer H, Ernsberger U (2013) Synaptic protein and pan-neuronal gene expression and their regulation by Dicer-dependent mechanisms differ between neurons and neuroendocrine cells. Neural Dev 8:16. doi:10.1186/ 1749-8104-8-16

Thermann R, Hentze MW (2007) Drosophila miR2 induces pseudopolysomes and inhibits translation initiation. Nature 447:875-878. doi: $10.1038 /$ nature 05878

Tiveron MC, Hirsch MR, Brunet JF (1996) The expression pattern of the transcription factor Phox 2 delineates synaptic pathways of the autonomic nervous system. J Neurosci 16:7649-7660

Unsicker K, Krisch B, Otten U, Thoenen H (1978) Nerve growth factorinduced fiber outgrowth from isolated rat adrenal chromaffin cells: impairment by glucocorticoids. Proc Natl Acad Sci U S A 75:34983502

Vinores SA, Marangos PJ, Parma AM, Guroff G (1981) Increased levels of neuron-specific enolase in PC12 pheochromocytoma cells as a result of nerve growth factor treatment. J Neurochem 37:597-600

Visvanathan J, Lee S, Lee B, Lee JW, Lee SK (2007) The microRNA miR-124 antagonizes the anti-neural REST/SCP1 pathway during embryonic CNS development. Genes Dev 21:744-749. doi:10. 1101/gad.1519107

Yu J-Y, Chung K-H, Deo M, Thompson RC, Turner DL (2008) MicroRNA miR-124 regulates neurite outgrowth during neuronal differentiation. Exp Cell Res 314:2618-2633. doi:10.1016/j.yexcr. 2008.06.002

Zehir A, Hua LL, Maska EL, Morikawa Y, Cserjesi P (2010) Dicer is required for survival of differentiating neural crest cells. Dev Biol 340:459-467. doi:10.1016/j.ydbio.2010.01.039 